\title{
The virtual industrial/organizational psychology class: Learning and teaching in cyberspace in three iterations
}

\author{
DONALD A. HANTULA \\ Temple University, Philadelphia, Pennsylvania
}

\begin{abstract}
The virtual industrial/organizational psychology course is an asynchronous, discussion-based undergraduate class that exists on the Internet, featuring lectures and class discussion in a Usenet group. The development, evolution, and successes and challenges from three iterations of this virtual course are described. While networked computer technology has enabled virtual classrooms for collaborative learning in which learners and teachers interact through computer-mediated communication, perhaps the most intriguing aspect of this course is the issue of experiential learning. In the virtual industrial/organizational psychology course, students are experiencing the organization of the future (networked, virtual) while learning about industrial/organizational psychology and the conceptual underpinnings of the world of work in the future.
\end{abstract}

Networked computer technology has enabled "virtual classrooms" for collaborative learning in which learners and teachers interact through computer-mediated communication. The virtual classroom concept has been evolving for at least 10 years (Hiltz, 1986, 1995), and exponential growth in Internet use has greatly facilitated development of virtual classrooms, especially within nontechnical disciplines (e.g., Ball, 1995). Although often implemented as part of a university-wide local network (see, e.g., Turoff, 1995), proliferation of powerful, relatively low-cost personal computers and platform-independent Internet media make the virtual classroom a viable option for interactive distance learning.

This paper describes three iterations of one such course, the virtual industrial/organizational (I/O) psychology course. Rapid changes in the university information infrastructure, university administration, Internet technologies, and personal computer software precipitated adaptations for each iteration. Lessons learned from each previous iteration of the course were applied to refining the next offering, while also incorporating modifications engendered

\footnotetext{
A brief version of this paper was presented at the 1997 meeting of the Society for Computers in Psychology in Philadelphia. Initial development of the virtual industrial/organizational psychology class was supported by a fellowship awarded by the Lilly Endowment. Additional funding for this project has come from the Teaching Learning Technology Roundtable and Distance Learning Committee at Temple University. I thank Ellyn Brecher and Nick DiFonzo for their comments on this manuscript; virtual TAs Ellyn Brecher and Tom Schoenfelder for their invaluable assistance; colleagues Phil Hineline and Dave Kipnis for their support; Stan Horwitz, Sheri Stahler, and the Help Desk at the Temple University Computer Center for their patience with my students and myself; and especially the students in the virtual industrial/organizational psychology class for their sense of humor and adventure. Correspondence should be addressed to D. A. Hantula, Department of Psychology, Weiss Hall (265-67), Temple University, Philadelphia, PA 19122 (e-mail: hantula@astro.ocis.temple.edu).
}

by external influences. Because the course was not intended to serve as a research project per se, course evaluation procedures changed as needed to conform to institutional requirements, and modifications to the course were made for educational, not analytical, purposes. Further, institutional regulations prohibited teaching courses in different formats for purposes of comparison; consequently there are no data in this paper from a direct comparison of a virtual versus "traditional" course. Thus, this report may be best considered as a formative evaluation (Gagne \& Briggs, 1979) of a course in constant pedagogical progress.

\section{THE VIRTUAL I/O PSYCHOLOGY COURSE}

The virtual $\mathrm{I} / \mathrm{O}$ psychology course is an asynchronous, discussion-based undergraduate introduction to the field of industrial/organizational psychology. As a sophomore/junior-level survey course, the material covered includes standard I/O subject matter such as job analysis, selection, training, motivation, conditions of the work environment, consumer behavior, and ergonomics. Many of the trappings are typical for such a class; required readings include an I/O textbook (Auerbach, 1995), the Wall Street Journal, and a small selection of articles from professional and scholarly journals (e.g., Daniels, 1985; Komaki, Desselles, \& Bowman, 1989). Attendance and participation are required, as are written midterm and final examinations.

The course is offered each spring semester. Semesters are 14 weeks long (excluding any breaks). Most of the students in the course are psychology majors, although students majoring in other fields of the arts and sciences, business, communications, dance, and pharmacy have completed the course. The prerequisite for the course is an introductory psychology course, although this requirement is waived for students with significant work experience. Computer expertise or experience is not a prerequisite 
For all three iterations of the course, the first 2 weeks of the semester were dedicated to training functional computer skills. In four 75-min classes, a programmed texttype manual was used to teach students to log on and log off from the university UNIX systems, use PINE to send and receive e-mail, subscribe and post to Usenet groups, manage files on their UNIX account, and use LYNX to browse the World-Wide Web. These sessions were optional for students who could perform all of the skills. After these four class sessions (from Week 3 onward), the class turned to learning the subject matter of $\mathrm{I} / \mathrm{O}$ psychology.

\section{Design Philosophy}

The technology is not the major focus of the course. Much of the technology used is fairly basic; that is, a Usenet group based on the university news server, a UNIX mainframe system and its native mailer and newsreader (PINE), and a variety of Web browsers from LYNX to Netscape. Rather, the emphasis is on assembling the technology to create a functional virtual classroom. Availability, interactivity, and saliency are the guiding design principles.

Availability. Many students or their families do not own computers and must rely on publicly available computers to access the course, although the number of students owning computers has increased each time the course has been offered. Some state-of-the-art equipment is available in laboratories with restricted access; however, the vast majority of equipment accessible for general student use is not as current. For example, during all three iterations of the course, the computers in the psychology department's student laboratory have been 386 class machines running DOS, not Windows. Given these technological limitations, most of the material is text based in order to provide ready access to the course. Class consists of postings on a university-based Usenet group, and as the Internet has been more integrated into the course, it is done so cautiously. The least common technological denominator principle (deliberately staying two steps behind the technological curve) has been employed when preparing each iteration of the course (e.g., using Windows 3.1 applications when Windows NT is the current standard).

Interactivity. Active engagement with course material has long been known to be a critical component of effective teaching (Keller, 1968; Skinner, 1968). Unfortunately, this appears to be often forgotten in many computerbased educational endeavors (Sims, 1997), although recent research in computer-based instruction has shown that requiring active responses from students improves learning (Tudor, 1995), recall (Kritch, Bostow, \& Dedrick, 1995), and generalization to later application of knowledge (Tudor \& Bostow, 1991). A major purpose of the virtual I/O psychology course was to use technology to facilitate interaction between students and the course material. Accordingly, the course was designed to be discussion based; to "attend" means to participate by posting to the Usenet group. Whether as an individual's reaction to a lec- ture or as a discussion between 2 or more students, written interaction with the course material defined the activity called "class."

Consequently, developing a virtual course is much more complex than taking traditional classroom-based course lectures and materials and transcribing them for use on a networked computer system. Differences between face-to-face and computer-mediated group discussion (Hightower \& Sayeed, 1995) demand that the asynchronous and visual nature of the medium be given close attention when one is arranging material intended to engender on-line discussion. Indeed, personal experience has shown that more traditional physical classroom-based lectures appear somewhat silly when reproduced verbatim on a Usenet group. Rather, it is critical to adapt the textual material to maximize active responding on the part of the students.

Several effective presentation strategies for on-line lectures that have evolved during the iterations of the virtual I/O psychology course are (1) breaking major points into small, easily read paragraph units; (2) making paragraphs no longer than a screen of text each; (3) including direct questions about the material often; (4) using white space to highlight or separate material; (5) positioning text about the screen at places other than flush left for emphasis and variety; and (6) including direct requests for responding to various parts of the lecture or to the textbook. Asynchronous interaction can be disconcerting to students, especially in the beginning. Often students' first posts will be of the "is anybody out there?" variety. Frequent instructor feedback, particularly reinforcement of especially good posts, or of any posts showing improvement in style and content, is critical to shaping and maintaining discussion. The feedback need not be any more than a one-line e-mail recognizing a positive aspect of the student's post. As might be expected, frequency and immediacy of feedback are far more important than the length of the message.

Saliency. Keeping the course material salient is of utmost importance, especially in the virtual classroom environment. It is easy, especially with novice computer users, for the technology to overwhelm the academic content of the course. Intense graphics, sound, and animation can often draw attention away from the comparatively mundane nature of an academic discipline. A Usenet group is textual, and because PINE (a text-based program) was used as both a mailer and a newsreader, the daily interactions with the technology were not especially distracting. "Virtual field trips" to various sites on the Internet are used to highlight a specific issue or illustrate a particular principle and are undertaken only after text and lecture material have been read.

\section{COURSE ITERATIONS}

\section{First Iteration}

Class and students. In the spring semester of 1995 , the first iteration of the virtual I/O psychology course 
Table 1

Student Evaluation of the First Iteration

\begin{tabular}{|c|c|c|c|c|}
\hline \multicolumn{5}{|l|}{ Question } \\
\hline Section 1 (Answers on a 1 [negative] -5 [positive] scale) & $M$ & & $S D$ & \\
\hline The course format. & $\overline{4.3}$ & & 0.8 & \\
\hline The initial computer training. & 4.3 & & 0.8 & \\
\hline Interaction with professor. & 4.2 & & 0.9 & \\
\hline Interaction with fellow students. & 2.7 & & 1.3 & \\
\hline Understanding of computers and their implications for organizations. & 4.4 & & 0.6 & \\
\hline Understanding of industrial/organizational psychology & 4.4 & & 0.9 & \\
\hline Access to computers and dial-in network & 3.8 & & 1.2 & \\
\hline Section 2 (answers on a yes/no scale) & & $\%$ Yes & $\%$ No & $\% \mathrm{NA}$ \\
\hline Did you or your family own a computer before you started this class? & & 46 & 54 & 0 \\
\hline Did you or your family own a modem before you started this class? & & 24 & 76 & 0 \\
\hline Did you or your family purchase a computer this semester? & & 16 & 84 & 0 \\
\hline Did you or your family purchase a modem this semester? & & 23 & 77 & 0 \\
\hline Before the start of the semester, had you ever logged on to a computer? & & 54 & 46 & 0 \\
\hline Before the start of the semester, had you ever sent e-mail? & & 30 & 70 & 0 \\
\hline Do you plan to keep your log-on id and/or commercial on-line service after the semes & r ends? & 77 & 23 & 0 \\
\hline Did you know this class would be offered over the Net before you came to the first & ass? & 23 & 77 & 0 \\
\hline Did you send e-mail to people not in class during the semester? & & 70 & 30 & 0 \\
\hline Are you more interested in learning about computers than at the start of the semeste & & 84 & 16 & 0 \\
\hline Are you more interested in learning about $\mathrm{I} / \mathrm{O}$ psychology than at the start of the ser & ester? & 77 & 16 & 7 \\
\hline As a result of this class are you more interested in a career in $\mathrm{I} / \mathrm{O}$ psychology? & & 54 & 39 & 7 \\
\hline As a result of this class are you more interested in a career involving computers? & & 46 & 46 & 7 \\
\hline As a result of this class are you more comfortable using computers? & & 85 & 7 & 8 \\
\hline Should in-class examinations be given if this class is offered again? & & 54 & 39 & 7 \\
\hline Would you take another virtual class? & & 85 & 7 & 8 \\
\hline Would you recommend this virtual class to a friend? & & 85 & 7 & 8 \\
\hline Should PSYCH 170 be offered again as a virtual class? & & 85 & 7 & 8 \\
\hline
\end{tabular}

was offered. Enrollment was capped at 25, and 23 students enrolled in the course. Three dropped during the semester for a drop rate of $13 \% ; 1$ of the students who dropped withdrew from the university and 1 dropped for health reasons. Two students had browsed the Internet before taking the course and 4 had either sent or received e-mail. All students were full- or part-time undergraduates living in the metropolitan Philadelphia area, with the exception of 1 student who audited the class from Texas.

Technology and procedure. The university's information infrastructure largely consisted of a 9600-baud network, and dial-up connections were available at that speed. The majority of computers available for student use were $x 86$ class machines, many running DOS. Graphic Web browsing capability was limited; while LYNX was used as browser on the system for dial-up use, Mosaic and Netscape were available in some computer laboratories.

Training in computer use occupied the first four class sessions. After the computer training, class consisted of virtual lectures posted to a Usenet group, ongoing discussion on the Usenet group, and "in-class" exercises. Three written examinations were given in a classroom on campus. Students were also required to subscribe to and participate in (post at least once) an additional LISTSERV or Usenet group of their choice.

Successes. This was the first virtual course offered at Temple University. Administrators and faculty colleagues expressed reservations about the viability and operation of such a course (hence the classroom-based examinations), and students questioned the wisdom of teaching psychology in such a technological manner. An anonymous evaluation of the course completed after the final examination (shown in Table 1) was positive. The majority of students said that the course should be offered again in a virtual environment, that they would recommend the course to a friend, and that they would be interested in taking another virtual course. Further, students rated their understanding of I/O psychology at 4.4 on a 5-point scale. Grade distribution was not different from a previous offering of this class in a traditional classroom by the same instructor or by a different instructor. Narrative comments regarding course procedure (not content) from the evaluation (shown in Table 2) identified flexibility, discussion/expressing ideas, and learning computer use as particularly positive features.

Challenges. Although class occurred in the Usenet group, three written examinations were administered in a classroom on campus. During the week when the second examination was scheduled, the regional mass transit system (bus, subway, and train) went on a 14-day strike (Fish \& Duvoisin, 1995), which made it difficult for many students to complete this examination. In narrative comments from the evaluation (shown in Table 2), students expressed frustration at the lack of graphic Web browsing capabilities, difficulty accessing computers on campus, and problems with dial-up connections. Students cited course flexibility as a positive feature, but also noted a need for increased self-discipline.

Discussion. The first iteration of the course was intended as a demonstration project to determine the fea- 
Table 2

Summary Narrative Evaluation Comments From First Iteration

\begin{tabular}{|c|c|}
\hline Positive Features/Advantages & Negative Features/Disadvantages \\
\hline Less pressure. & Limited interaction with fellow students. \\
\hline Classroom (finally) comfortable setting. & Easy to procratinate/need much more self-discipline in this class. \\
\hline Flexibility/work at my own pace/can work from home. & Acces to library computers is too competitive. \\
\hline Now feel more comfortable/less fearful with computers. & Psychology department needs more computers in building. \\
\hline Learned to use e-mail/browse internet. & Graphical access to Net not available. \\
\hline Professor always answers my questions quickly. & Should use some sound and video. \\
\hline Good place for group discussions. & Primitive software/system too slow/difficulty dialing in. \\
\hline This course made me feel like a person with ideas, not a studen & Too easy to get lost \\
\hline Felt like I was in control of what happened. & In-class tests/mass transit problems. \\
\hline $\begin{array}{l}\text { PINE was easy to use. } \\
\text { Help Desk staff. }\end{array}$ & LYNX was difficult to use/confusing/ugly. \\
\hline
\end{tabular}

sibility of an undergraduate asynchronous virtual course. Positive reactions from students, faculty colleagues, and administrators were taken as evidence that such a course is a viable and useful means of instruction. Therefore, the basic model of a virtual course developed in the first iteration was used as a baseline from which modifications were made and evaluated.

Perhaps the most important outcome of the first iteration of the course was evidence that neither the instructor nor the students had to occupy the same spatial or temporal locus for class to occur. Study materials such as textbooks and readings were always available to the students, and class interactions could be reviewed whenever students had access to a computer. Such temporal and spatial flexibility could also be exploited to bring other resources into the class that would be difficult to access otherwise. Because I/O psychology encompasses both research and practice, one valuable resource for this class is guest lectures by practitioners in the field. However, in more traditional classes the availability of guest lecturers is often limited by location and time constraints. The virtual classroom does not have these boundaries. Thus, the goals of the second iteration of the course were to first replicate the previous year's success and to broaden learning opportunities by including virtual guest lecturers.

\section{Second Iteration}

Class and students. The second iteration of the virtual I/O course was offered in the spring semester of 1996. Enrollment was capped at 25, and 23 students enrolled in the course. One student dropped during the semester for a drop rate of $4 \%$. Four students had browsed the Internet before taking the course and 7 had either sent or received e-mail. All students were full- or part-time undergraduates living in the metropolitan Philadelphia area.

Technology and procedure. The university information infrastructure expanded to include more modems and new UNIX servers, as well as more computers with graphic Web access on campus. The psychology department remained on the 9600-baud network. LYNX remained the default browser for dial-up access; however, some students who owned PC-compatible machines used I-Comm, a Mosaic-like browser that does not require a SLIP connection. Access to Mosaic and Netscape was available in some computer laboratories.
Like the first iteration, computer training occupied the first four class sessions, class consisted of virtual lectures posted to a Usenet group, ongoing discussion on the Usenet group, and in-class exercises, and students were required to subscribe to and participate in (post at least once) one additional LISTSERV or Usenet group of their choice. Unlike the first iteration, three written examinations were administered as take-home (or take wherever) examinations posted to the Usenet group on a Thursday with answers e-mailed to the instructor by the following Monday.

Six virtual guest lecturers forwarded a lecture on their specialty area (e.g., personnel selection, consumer behavior) to the instructor to be posted to the class Usenet group. Virtual guest lecturers were professional acquaintances and practicing I/O psychologists recruited by posting a request for virtual guest lecturers on HRNet, the LISTSERV of the Human Resources Division of the Academy of Management. Depending on their preferences, virtual guest lecturers responded to student questions individually or through the instructor. Because access to the class Usenet group was limited to university accounts, virtual guest lecturers could not interact directly with the class.

On the basis of student input, more Web-based content was added to the class. A course home page with links to sites on the Web of interest to students in $\mathrm{I} / \mathrm{O}$ psychology and links to virtual field trip destinations was added. Virtual field trips sometimes supplemented guest lectures as students visited Websites maintained by the lecturer's employers to promote their products and services or Websites maintained by the lecturers that supported their consultancies. Additonal virtual field trips were scheduled during the semester to augment class material, with destinations including the U.S. Department of Labor, the Society for Industrial/Organizational Psychology, and other university pages. During the week consumer behavior was discussed, students were assigned to find a Website advertising or selling a consumer product of their choice and to "bring" the URL to class along with an analysis of the Website. Not surprsingly, the consumer Websites chosen were those extolling the virtues of different beverages, luxury cars, and recordings of popular music.

Students were also asked to keep and submit journals documenting their experience in the class. Because no in-class examinations were administered, the written in- 
Table 3

Summary of Journal Comments Regarding Class Procedure From Second Iteration

Positive Features/Advantages

Ability to express opinions freely/without interruption/without intimidation Improved writing skills.

Less time constraints/work at my own pace/take breaks when needed.

Interesting comments/dialogue from classmates.

Learned to use e-mail/browse Internet.

Professor is available in person.

Joined interesting LISTSERV/Usenet group.

Take-home examinations.

Virtual guest lecturers interesting/later contact

great/example of consultant's report fascinating.

Discovered Internet resources.

PINE was easy to use.

Help Desk very helpful.

Commercial Websites were great.
Negative Features/Disadvantages

Psychology department computers should be upgraded.

Procrastination too easy.

Hard to stay focused on class/computer labs too noisy.

Examinations should be returned quicker.

Modems often busy.

Feel isolated.

System is often too slow.

LYNX was difficult to use.

Replies to my posts by other students were too slow/too few.

Netscape not available in some computer labs.

Internet is a great source of distraction.

Library computer lab always crowded.

UNIX system confusing. class evaluation used in the previous iteration could not be used. An on-line version of the previous year's evaluation form was developed, but unforeseen procedural difficulties negated its use. Therefore, material from student journals was used as the primary evaluation source. Although these journals were not anonymous, Table 3 shows that the comments regarding the course procedure (those concerning course content or other issues are not included) were remarkably similar to the comments gleaned from the previous year's anonymous evaluations.

Successes. Successful replication of the virtual course resolved many questions that had been raised the previous year. The previous year's version of the class made students aware of the possibilities of taking a virtual class, and many of the students enrolled for purposes of using the class format to their advantage. Six of the students were returning students of nontraditional age with family and job responsibilities, 2 had disabilities that limited their access to campus, and 2 had children under 1 year old. More than half of the students indicated that their primary reason for taking the course was to learn how to use the computer. The "take-wherever" examinations did not change the grade distribution significantly from that of the previous year.

The comments summarized in Table 3 show that the upgrades to the course were well received, especially the virtual guest lecturers. Students appreciated the practicioners' perspectives on theoretical issues and on the practice of $\mathrm{I} / \mathrm{O}$ psychology. One virtual guest lecturer allowed the class access to his organization's proprietary Website product for a week and another provided a copy of a recent consulting report completed for a client (with identifying material removed). All of the virtual guest lecturers answered student questions and corresponded with students after "their week" lapsed. Virtual field trips to Websites and analysis of consumer-focused Websites also proved to be both educational and enjoyable.

Challenges. Table 3 shows that technological difficulties were in the forefront. With the Internet's nearly exponential growth in popularity, accessing computers on campus or dialing in became more difficult. The limited university information infrastructure made assignments involving visits to graphic-intensive Websites especially demanding for some students. An Internet Relay Chat (IRC) problem during the semester made the university network inaccessible at random times. The dichotomies of self-pacing/self-discipline, and the Web as a source of information/source of distraction were also noted as significant issues for students.

Discussion. The second iteration provided a successful replication and extension that established the virtual I/O psychology course as an ongoing part of the curriculum. On-line courses began to be developed and offered by other departments throughout the university. In 1996 the university embarked on a number of technological initiatives, including establishing an Online Learning (OLL) office to promote on-line courses (either computerbased or videoconference) and introducing touch-tone telephone registration. The OLL office provided funding for course development, a dedicated server for on-line courses, and also demanded that OLL classes adhere to certain design mandates.

\section{Third Iteration}

Circumstances conspired to spur another course upgrade. In the second iteration, increased use of the Internet as an instructional resource was noted as a very positive component of the course. During the second half of the course, students became interested in creating their own home pages. Some students met with the instructor for informal lessons in HTML and then created personal Web pages or pages for student organizations. A colleague in the architecture department had offered a virtual course in computer-aided design (CAD) that year in which students uploaded their assignments to Web pages for class members to view and critique. With the significant technical advances in the university information infrastructure, the relative ease of learning basic HTML and growing interest in students becoming more Web literate, an option to write a course-specific Website ("the 21 st-century term paper") was added to the third iteration.

Class and students. The third iteration of the virtual I/O course was offered in the spring semester of 1997. Enrollment in the course was capped at 25; however due to 
Table 4

Summary of Journal Comments Regarding Class Procedure From Third Iteration

\begin{tabular}{ll}
\hline \multicolumn{1}{c}{ Positive Features/Advantages } & \multicolumn{1}{c}{ Negative Features/Disadvantages } \\
\hline Can attend Temple from out of state. & Too many students in class. \\
Child birth/care did not interrupt studies. & Too much work/too many messages to read. \\
Finish degree without interfering with work. & Always a wait for library computers. \\
Classmates helpful in getting me connected. & Too many postings are irrelevant. \\
Learned to use e-mail/browse Internet/write my own Web page & Computers in psychology department lab not working/need upgrading \\
Professor is available and helpful. & Would like more feedback on what I say. \\
Take-wherever examination. & Some computers on campus unreliable/too slow. \\
Able to take another class at this class time. & SLIP/PPP connection always busy. \\
Able to discuss my opinions about the reading. & Too much junk on the Net/too many students posted junk to class; \\
Can think about what I want to say. & students are rude to each other. \\
Can go to class when I am sick. & Server crashed a lot. \\
Websites on field trips were great. & Procrastination. \\
Commercial Websites were great. & Making the Web page was difficult. \\
& I miss seeing the professor and students. \\
\hline
\end{tabular}

difficulties with the new telephone registration system, 52 students enrolled in the course. Eight dropped during the semester for a drop rate of $15 \% ; 1$ of the students who dropped withdrew from the university, 1 dropped as a result of a serious car accident, 1 dropped because the course would not count toward graduation, and 3 dropped due to difficulties accessing computers or dialing in. Twentyfour students had browsed the Internet before taking the course and 40 had either sent or received e-mail. Most were full- or part-time undergraduates living in the metropolitan Philadelphia area, and others lived in New York, northern New Jersey, or Virginia. A cooperative local bookstore agreed to ship class books and other materials to out-of-state students, which facilitated their participation in the class.

Technology and procedure. The university information infrastructure was greatly improved when this iteration of the class started. Student laboratories equipped for graphic Web access were expanded, and a dial-up SLIP/PPP connection for machines running Windows 95 or Macintosh System 7.1 was brought on-line. However, the psychology department remained on the 9600-baud network. As in the first two iterations, computer training occupied the first four class sessions, and class consisted of virtual lectures posted to a Usenet group, ongoing discussion on the Usenet group, and "in-class" exercises. The course Website with links to locations on the Web of particular interest to students of I/O psychology was updated and expanded. Two written examinations were administered as take-home (or take-wherever) examinations posted to the Usenet group with answers e-mailed to the instructor. The third examination required in the first two iterations was dropped in favor of an option to submit either a term paper on a topic in I/O psychology or develop a course-specific Website (" 21 st-century term paper" option) illustrating a topic in I/O psychology.

As with the previous iteration, students kept and submitted journals documenting their experience in the class. The OLL office assumed responsibility for evaluating on-line courses and developed a Website for that purpose.
Unfortunately, these evaluation efforts were directed largely toward programmatic concerns for all OLL courses and data were aggregated across all OLL courses offered that semester. Again, material from student journals was used as the primary evaluation source. Summaries of comments regarding the course procedure (those concerning course content or other issues are not included) are shown in Table 4.

Successes. Despite the unexpected throng, the course ran well. The virtual guest lecturer feature was dropped due to anticipated logistical problems associated with mediating between the larger class and the guest lecturers. The course's flexibility appeared to be an advantage to more students. Four of the students were returning students of nontraditional age with family and job responsibilities, 1 had a disability that limited access to campus, 3 had children under 1 year old, and 1 student had a baby during the semester, as did another student's partner. Due to the number of students who had previous experience using computers, the beginning of the class was not as trying as expected. Minimal instruction in HTML was given, but with the help of Creating Web Pages for Dummies (Smith \& Bebak, 1996), all but 2 students opted to create a Website illustrating a topic in $\mathrm{I} / \mathrm{O}$ psychology rather than submitting a traditional term paper. Grade distribution was not different from that of previous offerings.

As Table 4 shows, many of the student comments echoed those from previous iterations. For this iteration, however, more students appeared to have enrolled in the course explicitly because it enabled them to meet work, family, or academic responsibilities. Developing the Website in lieu of a term paper was cited by students as being both the most demanding and the most rewarding components of the class. One student used her new HTML skills to create a Website for her business, 2 went on to author Web pages for student organizations, 1 invented a summer job as a freelance Web author, in personal communications with the instructor, 3 students remarked that their HTML skills led to full-time postgraduation employment, and approximately 10-12 have used these skills 
for their own self-expression, as evidenced by e-mails received in the months after the semester that said, "Hey Doc, check out my home page!"

Challenges. The carpeting in the psychology department's computer laboratory had been replaced right before the start of the semester. Unfortunately, this laboratory was used to teach computer skills in the first 2 weeks of the semester and most of the computers were disconnected from the network during the carpet replacement, leaving only two functional computers on the 1 st class day. This problem was not fully rectified until the next week. The day before the midterm examination was due, the university's news server crashed and was down for 1 week for hardware repairs. Students were confused and frustrated, and class was essentially canceled for a week. Competition for access to public computers and to dial-up connections increased markedly to the point that the library's computer center began issuing beepers to students who were waiting for computers so that these students could study elsewhere in the library or get a meal while waiting.

Many of the comments on the right side of Table 4 give some insights as to how the large class size strained time and resources over the course of the semester. In some weeks, there would be over 100 posts to the Usenet group, which made for an arduous workload for instructor and students alike. Also, disagreements and digressions became a serious drain on students' time. For example, a student posted to the class material from a Website that supposedly "exposed" corporate wrongdoings such as Proctor \& Gamble's alleged allegiance with Satan and Snapple's alleged association with the Ku Klux Klan. The cascade of replies and counter-replies became quickly vituperative and detracted from the class.

\section{LEARNING IN CYBERSPACE}

In 3 years, student familiarity with the technology went from virtually none to a majority of those enrolled in the class. Part of this was probably due to a self-selection process as the virtual I/O psychology course became better known around campus. However, at least at this time and place, it cannot be readily assumed that all students have the necessary skills to succeed in an Internet-based course. Even those students who had some experience with computers, e-mail, and the Internet required some instruction to be able to complete their work. Indeed many students cited learning how to use computers and the Internet as a primary reason for taking the course.

The university's information infrastructure and administration also evolved during this period. The number of publicly available machines increased markedly and graphic Internet access became available in the majority of student laboratories and at home through SLIP/PPP dialup. However, while Pentium-based machines appeared in student laboratories, a sizable number of 486 class machines remained in these laboratories and were frustratingly slow processing graphic Web pages. As the infrastructure improves, more Web-based material can be brought into the course. Because student reaction to using the Internet as a learning resource was very positive, virtual field trips will continue, as will further exploration in using Web-based information such as the data from the U.S. Bureau of Labor Statistics. Beyond serving as a virtual library, the Website/term paper in the third iteration showed that the Web can be used as a medium for student scholarship. Administratively, the university moved from skepticism to active support of on-line educational initiatives. Whereas the first iteration of the course was the sole on-line course offered, the third iteration was 1 of 13 offered that semester.

Perhaps one of the most difficult lessons to learn is how to exist in cyberspace (Gibson, 1984); yet it is an important lesson. In this course, students need not ever see or meet one another or the instructor. The lack of a physical presence and the asynchrony proved disorienting to many students. Some students reported forming small groups that would meet regularly, while others would routinely drop by the instructor's office "just to see if you are still there." Because Internet skills and computer literacy are not prerequisites for the course, the computer skill training in the beginning allowed some students to interact physically among themselves and with the instructor. However, for students with the requisite skills, the initial meetings were optional, and indeed half of those in the third iteration did not attend. It should be noted that none of the students who did not attend the initial meetings has dropped the course. The issue of comfort in a virtual environment may be a function of skill and experience.

Clearly, students in this course learned how to interact on the computer and acquired "cyber survival skills." As the business and professional world becomes more networked (Cronin, 1994; Sterne, 1996), such skills provide a competitive edge for most students and are even mandatory in certain pursuits. This is an especially important advantage for students majoring in fields that are not yet technologically intensive at the undergraduate level, such as a general psychology major. But, as admirable as these outcomes may be, they should not overshadow course content.

The extent to which students learned I/O psychology may be assessed by triangulating several indirect indices. Although the first 2 weeks of the course were devoted to computer skill training, the same amount of material was covered as in a more traditional, classroom-based course. Examination of previous syllabi in more traditional I/O psychology courses taught by the instructor showed that more than 4 class days were dedicated to other educational endeavors. For example, the first class meeting was abbreviated and given over to "opening ceremonies"; $2-3$ classes were used for examinations; and an additional 2-3 classes were used for experiential exercises or other inclass activities. In all three iterations, grade distributions did not differ, nor were they different from those of previous I/O psychology courses taught by the instructor. Granted, grades could have been engineered to produce this outcome, but it is unlikely. Attending class required 
constant interaction with the material. Throughout the semester, students were writing about method and theory in $\mathrm{I} / \mathrm{O}$ psychology and reading and commenting on one another's ideas. Examinations required integration of concepts and application. And, although student ratings of their own learning are often inexact, as shown in Table 1, students in the first iteration rated their understanding of $\mathrm{I} / \mathrm{O}$ psychology at 4.4 on a 5 -point scale. Thus, the indirect evidence appears to indicate that even with the initial emphasis on computer skills and the technologically intensive medium, substantive content was not given short shrift.

\section{Experiencing the Future}

Perhaps the most intriguing aspect of this course is the issue of experiential learning. In the virtual I/O psychology course, students are experiencing the organization of the future (networked, virtual) while learning about I/O psychology and the conceptual underpinnings of the world of work in the future. Experiential learning is a longstanding tradition in teaching organizational behavior (Fleming, 1992). Through experiential learning, students learn skills, but may also develop a fuller awareness of their own behavior.

To facilitate reflection on their experience in the virtual classroom, students kept a journal (Ramsey \& Couch, 1994) with the following minimal requirements listed in the syllabus as a required part of the course:

1. At the end of the semester (day of the final examination), students will submit electronically a journal consisting of their own thoughts and reflections on the course material, experiences during the course, and other relevant information.

2. This journal is intended for you to keep a running log of how you are adapting to life on-line. It is not a simple reiteration of your posts to the Usenet group about the material, but rather is a running dialogue with yourself about your experiences.

3. You should make entries in your journal at least weekly.

Summaries of journal comments regarding the course procedure are shown in Tables 3 and 4 . Review of the journals after the semester ended showed that students did in fact reflect on their experiences in the class and remarked about changes in their views of technology, on-line learning, and virtual interaction. In general, for students who were not technologically adept from the start, excitement, bewilderment, fear, and frustration were reported at the beginning of the semester; challenge, persistence, acceptance, and alienation were reported around the middle of the semester; and challenge, accomplishment, relief, and enthusiasm were reported at the end. Technologically experienced students expressed excitement and anticipation at the beginning of the semester, and throughout the semester expressed enjoyment and expectations for futher on-line learning or working ventures.

To reinforce experiential learning of the course content, explicit ties between the course material and the in- structional medium were emphasized. For example, when discussing ergonomics, students were asked to perform a brief assessment of the ergonomic aspects of their on-line workspace and to suggest improvements; consumer behavior principles were illustrated by field trips and analyses of consumer-focused Websites, and computerized testing was discussed in the chapter on employee selection.

Changes in technologically based work arrangements occur so quickly that once they are documented in trade or text books, they are usually passé. From reading the Wall Street Journal, a daily newspaper that features a weekly personal technology column as well as regular articles discussing on-line management and commerce issues, students got a feel for how they were learning about the future as it occurred. Indeed, on the evaluation form for the first iteration of the course, 1 student wrote, "I felt like we were in an I/O experiment that worked." Most experiential learning exercises or classes occur in a classroom or classroom-like setting in which all of the participants are gathered together. However, with the proliferation of flextime, home offices and other virtual work arrangements (Cronin 1994), it is probably time to question the adequacy of classroom-based experiences for students who may very well be headed to virtual work arrangements.

\section{TEACHING IN CYBERSPACE}

Students enter the virtual classroom with wide-ranging experience and expectations, from computer literate and enthusiastic to entirely inexperienced and somewhat computer phobic. Simply exposing the less experienced and enthusiastic students to computer use in psychology may not have much of an effect on their attitudes or use of computers (Rosen \& Petty, 1995). Thus, the first 2 weeks were dedicated to gradual skill building, while a good part of the semester was devoted to building comfort.

\section{Being There}

The asynchronous nature of the course demands from students a higher degree of self- management skills than do many other classes, which was noted by students (Tables 2-4). The degree to which such mundane features of the collegiate environment as uncomfortable desks, chalkboards, close physical proximity to other students, regular class meetings, and a physical classroom support and maintain academic behavior is remarkable. Without these common academic artifacts, students can find it difficult to sustain academic performance over the course of the semester. Each semester, some students "get lost" but usually return. It is notable that in 3 years, only 1 student dropped the course due to irredeemable procrastination.

Science fiction author William Gibson (1984, p. 36) seemed to anticipate this when he coined and defined the term cyberspace as "a consensual hallucination experienced daily by billions of legitimate operators, in every nation, by children being taught mathematical concepts. . . . A graphic representation of data abstracted from the 
banks of every computer in the human system. Unthinkable complexity. Lines of light ranged in the nonspace of the mind, clusters and constellations of data. Like city lights, receding."

Although the typical physical features of the classroom environment are not present, those in the virtual classroom begin to behave as if the rather typical relationship called "class" is occurring. Making the virtual classroom real for students seems to involve a high degree of feedback and reinforcement for "being there" such as posting messages, asking questions, and raising points of discussion, especially at the beginning of the semester. Ironically, while at first glance the virtual classroom may be criticized as impersonal, students in this course and in others (see, e.g., Maki \& Maki, 1997) report professors' being more available and having more personal contact and attention than in more traditional lecture courses.

Close monitoring of virtual attendance and prompting those students who fall behind is an important management task in this medium. Having students post an introductory message describing themselves to the class also seems to make the transactions in the virtual classroom more real. Compiling and providing a Web page with "mail-to" links of all students in the class was suggested by a student in the first iteration to provide a "classroom" to which students could go to find their classmates. However, the degree to which students experience reliable consequences for their on-line behavior is probably the most important variable in determining how real the on-line class becomes.

\section{For Instructors Only}

The first step toward developing a successful virtual course is not to look for ways to use the most current technology, but rather to ponder the questions, "Given the technology that is readily available to my students now, what can we do that we could not do before?" and, "Given the current institution and student population, is it worth doing?" Once those answers are thought through, several operational aspects should be considered.

Developmental details. The virtual I/O psychology course has been discussed in the context of changing administrative and technological influences, but it should also be considered in the context of the individual instructor's development. Teaching with technology has been a career-long occupation (see, e.g., Hantula, Boyd, \& Crowell, 1989), making this course a logical next step. Even so, the up-front costs in terms of time and effort should not be underestimated. This course was developed during a one-course teaching reduction, and refined during a second one-course teaching reduction. For instructors who have not had much experience teaching with technology, it would not be unreasonable to expect course reduction for two consecutive semesters for both personal course development purposes.

Technology and the teacher. The virtual class instructor need not be a computer scientist, but should be thoroughly comfortable with the technology used in the class. The instructor's level of technological comfort is critical; students in technologically intensive classes report more positive learning outcomes and rate their instructor more favorably when the instructor exhibits a positive attitude toward the technology and can control the technology (Webster \& Hackley, 1997). Minimally, the instructor should be facile with the programs students use and be able to instruct students in their use. Realistically, the instructor should be technologically knowledgeable enough to anticipate and solve common problems that novice users will encounter because the instructor is the person with whom students will feel most comfortable when the inevitable technological difficulties arise. For example, although students in the first two iterations of the virtual course cited the computer center's help desk as a positive feature, technical questions were often directed to the instructor. Even in an organization offering expert and easily accessible technical support, a competent instructor is one who can help students work through their technical travails. Nonetheless, a professional and knowledgeable help desk staff is a worthwhile investment for any university serious about on-line learning.

One particular technological aspect of the course is worthy of note; Usenet was employed as the masscommunication program instead of LISTSERV. Although LISTSERV is a popular technology for discussion groups and classes, it can also be frustrating. LISTSERV is a "push" technology that broadcasts all messages sent to the listserver to all subscribers, which can result in much junk mail as well as overloaded mailboxes that may send overload notices back to the listserver, which are again distributed. In contrast, a Usenet group is a "pull" technology in which users must seek out each time they wish to review messages. Junk may be posted to the Usenet group, but individuals mailboxes are not assaulted. Also, the PINE program functions as both a mailer and newsreader. In the PINE interface, the mail and news functions are well defined, and thus it is easy to discriminate between whether one is entering, or is in, mail or news. From the beginning, it is emphasized that the Usenet group (news) is public communication, whereas mail is private communication. This distinct delineation between modes of communication and interface used to support communication is likely responsible for the marked lack of misdirected mail to the Usenet group, a problem that is endemic to LISTSERV.

Student knowledge. Although URLs are ubiquitous in advertisements and the popular media appears flush with Web-speak, it should not be assumed that most students have basic Internet survival skills needed to succeed in a virtual course. This does not appear to be limited to the particular course, discipline, and institution described in this paper; even technologically intensive institutions are grappling with this issue (see, e.g., Blumenstyk, 1997). Two general solutions for this problem are (1) limiting enrollment to those students who can per- 
form the requisite skills, or (2) using the course as an opportunity to train necessary computer skills. The first solution has the obvious advantage of maximizing time for course content and minimizing frustration on the part of instructor and student alike. However, the second solution was chosen because it allowed students to learn necessary skills while performing an academically meaningful task. Rather than instructing students in generic "computer skills" at some other time and place, a contextualized environment was created to hopefully engender transfer and maintenance of these skills. To accomplish this goal, a programmed-text type course manual that decomposed tasks such as logging on, reading e-mail, and so on, into small individual steps was developed to teach necessary computer skills.

Time commitments. Beyond development time, teaching time in the virtual classroom is also an important consideration. Although teaching hours were not logged, by all appearances the time committed to the virtual I/O psychology course was at least equal to, and probably greater than, time devoted to a similar undergraduate course taught in a more traditional classroom environment. At the beginning of the semester, there must be additional time dedicated to helping students gain comfort and expertise, reinforcing initial attempts at communicating on-line, and managing the unforeseen but unavoidable operational accidents. Without a graduate teaching assistant and a cooperative help desk provided by computer services, time dedicated to this course could have easily doubled that of other courses, and more than tripled the time commitment in the third iteration. To the extent that this one instructor's experience is generalizable, a virtual classroom is not a viable means by which teaching and support costs may be cut. If anything, the virtual classroom raises these costs.

Teaching Assistants. The first and third iterations of the I/O psychology course were greatly enhanced by a graduate teaching assistant. Because a teaching assistant for this course has not been funded, these volunteers helped with the course in addition to their other responsibilities. With the instructor's guidance, teaching assistants created virtual lectures, answered student questions, taught computer skills, and maintained the course Website. As the demand for virtual courses grows, it is important that supervised and funded virtual teaching assistantships be created for the benefit of current students in virtual classes as well as to develop a future professoriate well versed in teaching with technology.

Authorship and ownership. In the first iteration inclass examinations were given because of administrative questions about validating authorship and ownership of the work. Although this is a legitimate concern, $40 \%$ of students' grades were based on discussion and postings in the Usenet group, authorship of which could not be validated entirely; thus the impact of cheating on examinations would be negligible. Given the negative student reaction to in-class examinations, coupled with the unfortunate mass-transit strike, the in-class examination requirement was reassessed. Realistically, in a large (e.g.,
$>100$ students) lecture section with in-class examinations, or in smaller classes that assign take-home examinations and papers, work is not monitored. Students can, and sometimes do, recruit friends or acquaintances to attend classes or complete examinations and assignments for them. Hence, although cheating can and will occur in college-level courses, the extent to which this may be a greater problem in a virtual class remains to be seen.

Teaching and research. The virtual classroom opens up new vistas for research in the context of teaching. The obvious (but wrong) question to address would seem to be that of a virtual course versus a traditional course. Although this may seem commonsensical, such a study would yield little useful knowledge because the constructs of "virtual course" and "traditional course" are ill-defined at best and have so much variation in execution that it is unclear exactly what features of each are critical and what is actually being compared (Johnston, 1988). Further, it is not clear that a "fair test" could be executed if the participants are proponents of one side or the other (Crossen, 1994). Even if current institutional policy had allowed such a study, we would not have conducted it.

However, within the virtual classroom, a socialpsychological analysis of human-computer interaction (see, e.g., Quintanar, Crowell, Pryor, \& Adamopoulos, 1982), computer-mediated interaction (see, e.g., Bordia, 1997), and of the computer interface (see, e.g., Quintanar, Crowell, \& Moskal, 1987) makes for ready research, as do questions of student reaction and change throughout a semester. When and the degree to which the class or subunits of the class coalesce as groups, the effects of taking a virtual class on student work and study routines, and attitudes toward computing and technology and writing skills are also open questions. These types of research questions are more analytical in nature than a comparison study and should also serve to provide data for both teaching improvement and scholarly publication, which may be an additional personal justification for the increased time devoted to a virtual course.

Subject matters. An overhead projector provides an excellent means for illustrating principles of visual perception. This in no way negates its use for teaching motivation. Likewise, although the virtual course described herein is in I/O psychology, it should not be implied that a virtual class is less valid for any other area of psychology (or any other subject, for that matter; currently Temple University offers virtual courses in subjects ranging from classics to economics). Maki and Maki (1997) described a virtual introductory psychology course, and certainly virtual courses in other areas of psychology exist. The technology in and of itself does not necessarily either limit or facilitate teaching a particular subject. Rather, the technology must be assembled and managed to meet the educational goals of the particular course.

Granted, in the current business and economic environment, Internet-related issues are at the forefront, a positive coincidence for this course, which was exploited for its experiential educational value. It is recognized that the virtual I/O psychology course runs perhaps the great- 
est risk of confounding the medium with the message. Yet, the virtual class environment appears to readily offer opportunities for experiential learning in courses in social psychology, learning, psychology of language, cognition, and additional courses that will be apparent to experts in other areas of psychology.

\section{DISCUSSION AND CONCLUSIONS}

Overall, the virtual I/O psychology course has been a successful endeavor. Although many of the students who have taken the course are "traditional" undergraduates, students from different states have completed the course, as have those with special circumstances such as disabilities, pregnancies, or work or family responsibilities. Drop rates were significantly lower than those in traditional face-to-face classes, and although more than half of the students entered the course with little to no computer skills, all finished the course able to use the Internet as a learning tool. Because the course is entirely based on the written word, students are afforded the opportunity to refine their writing skills. Students have evaluated the virtual I/O psychology course as a positive learning experience, although many find the lack of face-to-face interaction somewhat disconcerting. The asynchronous nature of the course has allowed the instructor to teach from a variety of locales in the United States and beyond.

Distance learning is not new. However, what makes the virtual I/O course and others like it new is the explicitly interactive (Bork, 1997) nature of the class. In most previous distance learning models (books, videos, audiotapes, etc.), interactivity was sacrificed for convenience. However, with the advent of the Internet and availability of powerful, low-cost computers, interactivity and convenience are no longer opposites, but can be complements. The virtual I/O psychology course combines a "hightech /high-touch" method by using the Internet, Usenet, and e-mail to facilitate interaction among students, the material, and the instructor as the mode of learning. The inputs to each class are unique in the form of student and instructor postings, so the course cannot be "canned" and packaged. The technology simply provides the framework for and facilitates discussion.

Likewise, computers in the classroom are not new; neither is using computers to complete or submit assignments. What is new is the network. The networked technology used in the iterations of this class ranged from the basic (e.g., PINE) to the edge (e.g., Netscape); however, it is not the technology alone that enables the virtual classroom, but rather the networking of technologies and individuals. Linking together student, instructor, guest lecturer, learning resources, and academic work product into a virtual classroom that defies traditional time-space constraints defines what is new and exciting about this medium.

The success of the virtual I/O psychology course and other similar courses raises some challenges to conventional wisdom, such as the role of computing in the university, the role of computing as a transferable tool of learning, the definition of the university, and the fallacy of spatiotemporal contiguity. Computing, broadly defined, extends beyond technical issues, data analysis, programming, and word processing to include using the computer as a tool to enable learning, research, and scholarship. Therefore, as virtual classes proliferate, it becomes increasingly important to equip students with a degree of computer literacy and sophistication that will enable them to continue to use digital tools to further their own knowledge and to provide for training the next generation of professors in this medium. Proliferation of virtual classes then calls into question the definition of the university in a digital age. Is the university a place, a group of buildings and people, or is the university a particular kind of relationship between people and institutions? Finally, although it is often assumed that people must physically gather in the same place at the same time for events such as class to occur, the success of the virtual classroom challenges this fallacy of spatiotemporal contiguity and suggests that such icons of education as "class" and "teaching" be considered more by their functional effects than by their structural characteristics.

\section{REFERENCES}

AUERBACH, A. (1995). The world of work: An introduction to industrial/ organizational psychology. New York: Brown \& Benchmark.

BALL, W. J. (1995). Using the Internet as a teaching tool: Why wait any longer? Political Science \& Politics, 28, 718-720.

BlumenSTYK, G. (1997, December 12). Florida Gulf Coast U. hopes to innovate in teaching, and to save money in the process. Chronicle of Higher Education, p. A23.

BoRDIA, P. (1997). Face-to-face versus computer-mediated communication: A synthesis of the experimental literature. Journal of Business Communication, 34, 99-111.

Bork, A. (1997). The future of computers and learning. T. H. E. Journal, 24, 69-77.

Cronin, M. J. (1994). Doing business on the Internet. New York: Van Nostrand Reinhold.

CRossen, C. (1994). Tainted truth: The manipulation of fact in America. New York: Simon \& Schuster.

DANIELS, A. (1985). Performance management: The behavioral approach to productivity improvement. National Productivity Review, 4, 39-49.

Fish, L., \& Duvorsin, M. (1995, April 11). How both sides gave to get a pact SEPTA set for full service today. Philadelphia Inquirer, p. A 1 .

FLEMING, R. K. (1992). An integrated behavioral approach to the transfer of leadership skills. Journal of Management Education, 16, 341-353.

Gagne, R. M., \& Briggs, L. J. (1979). Principles of instructional design (2nd ed.). New York: Holt, Rinehart \& Winston.

GibsoN, W. (1984). Neuromancer. New York: Ace Books.

Hantula, D. A., Boyd, J. H., \& Crowell, C. R. (1989). Ten years of behavioral instruction with computers: Trials, tribulations, and reflections. In J. Hodges (Ed.), Proceedings of the Academic Microcomputer Conference (pp. 81-92). Bloomington: Indiana University Press.

HightowER, R., \& SAYEED, L. (1995). The impact of computer-mediated communication systems on biased group discussion. Computers in Human Behavior, 11, 33-44.

Hiltz, S. R. (1986). The virtual classroom: Using computer mediated communication for university teaching. Journal of Communication, 36, 95-104.

Hiltz, S. R, (1995). Teaching in a virtual classroom. International Journal of Educational Telecommunications, 1, 185-198.

JoHnston, J. M. (1988). Strategic and tactical limitations of comparison studies, Behavior Analyst, 11, 1-9.

KELler, F. S. (1968). Goodbye teacher . . Journal of Applied Behavior Analysis, 1, 75-89. 
Komaki, J., Desselles, M., \& Bowman, E. (1989). Definitely not a breeze: Extending an operant model of effective supervision to teams. Journal of Applied Psychology, 74, 522-529.

Kritch, K. M., Bostow, D. E., \& DeDRICK, R. F. (1995). Level of interactivity of videodisc instruction on college students' recall of AIDS information. Journal of Applied Behavior Analysis, 28, 85-86.

MAKI, R. H., \& MAKI, W. S. (1997, November). Teaching introductory psychology on the web: Some preliminary evaluation results. Paper presented at the meeting of the Society for Computers in Psychology, Philadelphia.

Quintanar, L. R., Crowell, C. R., \& Moskal, P. (1987). The interactive computer as a social stimulus in human-computer interactions. In G. Salvendy, S. L. Sauter, \& J. J Hurrell (Eds.), Social, ergonomic, and stress aspects of work with computers (pp. 303-310). Amsterdam: Elsevier.

Quintanar, L. R., Crowell, C. R., Pryor, J. B., \& Adamopoulos, J. (1982). Human-computer interaction: A preliminary social psychological analysis. Behavior Research Methods \& Instrumentation, 14, 210-220.

RAMSEY, V. J., \& CouCH, P. D. (1994). Beyond self-directed learning: A partnership model of teaching and learning. Journal of Management Education, 18, 139-161.

Rosen, E. F., \& PeTty, L. C. (1995). The Internet and sexuality education: Tapping into the wild side. Behavior Research, Methods, Instruments, and Computers, 27, 281-284.
Sims, R. (1997). Interactivity: A forgotten art? Computers in Human Behavior, 13, 157-180.

SKINNER, B. F. (1968). The technology of teaching. Engelwood Cliffs, NJ: Prentice-Hall.

Sмith, B., \& BebaK, A. (1996). Creating Web pages for dummies. Foster City, CA: IDG.

STERNE, J. (1996). Customer service on the Internet: Building relationships, increasing loyalty, and staying competitive. New York: Wiley.

Tudor, R. M. (1995). Isolating the effects of active responding in computer-based instruction. Journal of Applied Behavior Analysis, $\mathbf{2 8}$ 343-344.

TudoR, R. M., \& Bostow, D. E. (1991). Computer-programmed instruction: The relation of required interaction to practical application. Journal of Applied Behavior Analysis, 24, 361-368.

TurofF, M. (1995). Designing a virtual classroom. International Journal of Educational Telecommunications, 1, 245-262.

WEBSTER, J., \& HACKLEY, P. (1997). Teaching effectiveness in technologymediated distance learning. Academy of Management Journal, 40, 1282-1309.

(Manuscript received October 21, 1997; revision accepted January 28, 1998.) 